\title{
Centro de Memória e Informação do Esporte: uma política de preservação da memória do esporte mineiro
}

\author{
Marilita Aparecida Arantes Rodrigues*
}

\begin{abstract}
Resumo
Neste artigo, discute-se a importância da informação e da preservação da memória na atualidade e analisa-se a constituição de centros de memória como lugar de preservação, pesquisa, comunicação, produção e reprodução de conhecimento histórico. Tem-se como foco o relato da experiência do Centro de Memória e Informação do Esporte - CEMIE -, criado pela Secretaria de Estado de Esportes e da Juventude de Minas Gerais - SEEJ -, como uma política pública de preservação da memória do esporte mineiro.
\end{abstract}

Palavras-chave: Centros de memória; Esporte; Política pública; Minas Gerais.

O modo como o Estado de Minas Gerais cuida da memória do esporte diz muito sobre como ele trata a sua própria história.

(VAGO, Tarcísio Mauro, 2008)

A informação ocupa uma posição de centralidade no mundo contemporâneo. Com base nela, os diferentes setores da sociedade se organizam e definem suas estratégias de ação. Ela é a matéria-prima para a tomada de decisões nas instituições, e a sua posse é sinônimo de poder. Nesse sentido, a preservação de informações e o acesso a elas são fundamentais para instituições, órgãos governamentais e empresas.

A preservação da memória é também uma das preocupações culturais e políticas centrais nas sociedades ocidentais. Nos últimos vinte anos, a velocidade das transformações e as incertezas quanto aos rumos que elas determinam provocaram um interesse crescente em conhecer e preservar os valores do passado. Houve uma efervescência de iniciativas voltadas para a preservação da memória em diversos níveis. Assim, o que se observa, hoje, é um grande interesse pela história, um fascínio pelo

\footnotetext{
* Doutora em História pela Faculdade de Filosofia e Ciências Humanas - FAFICH/ Universidade Federal de Minas Gerais - UFMG. Diretora de Memória e Informação da Secretaria de Estado de Esportes e da Juventude.
} 
passado, pela busca de raízes. Márcia D’Alessio (1993, p.97) destaca que “do senso comum às políticas públicas existe concordância sobre a preservação da memória [...]. Uma necessidade identitária parece estar compondo a experiência coletiva dos homens e a identidade tem no passado seu lugar de construção." Sem memória, não nos situamos no mundo, não entendemos quem somos ou como chegamos a ser quem somos.

Os museus e centros de memória viraram moda. Se voltarmos nosso olhar para a capital mineira, veremos que, há pouco mais de uma década, havia poucos museus na cidade. Hoje, pode-se falar não somente de um crescimento de museus, mas, principalmente, da criação de um grande número de instituições do gênero, como as casas de cultura e os centros de memória.

Para além desse crescimento, uma transformação significativa vem acontecendo nas estruturas das bibliotecas e dos museus, que estão sendo reinventados e transformados em espaços de cultura significativos e polivalentes para a população. Esses espaços permitem o acesso ao conhecimento, à discussão, à criação de novos conhecimentos e à difusão de novas informações, atendendo aos interesses da população. Se antes eram espaços de coleções, hoje são espaços de informação, de discussão e de criação. Como retrata Mário Chagas (2006), seus compromissos são não tanto com o ter e preservar acervos, mas, sim, com o ser espaço de relação e estímulo às novas produções.

Dessa forma, a preservação do patrimônio cultural para a formação de identidades culturais, o conceito de cidadania cultural, a cultura vista como direito dos cidadãos à fruição, à experimentação, à informação, à participação e à memória, são temas presentes nas discussões atuais sobre as ações dos museus, bibliotecas, arquivos e centros de memória.

O interesse pela memória tem se revelado, também, na articulação de redes de memória. Essas redes, baseadas em adesões voluntárias visando a cooperação, a troca de informações e experiências, as promoções conjuntas de cursos e seminários, o desenvolvimento de metodologias de trabalho, em relação a aspectos técnicos pertinentes à preservação da memória, e os espaços virtuais e físicos de discussão e integração de acervos, têm sido cada vez mais estruturadas.

Destaca-se, em nível estadual, a Rede Memória das Instituições de Minas Gerais - REMIG -, um grupo formado em 2003 que, atualmente redefiniu seu funcionamento em rede. O foco da Remig é a memória institucional. A rede tem recebido um grande número de adesões. Em âmbito nacional, destaca-se a Brasil Memória em Rede, 
constituída por instituições e pessoas que valorizam o uso da memória como ferramenta de desenvolvimento social e cultural do país.

Vivemos, assim, segundo Huyssen (2000), um período em que somos seduzidos pela memória. Os centros de memória, nesta era de informação e tecnologia, têm papel extremamente significativo a cumprir como centros de documentação e informação, com fundos e coleções organizadas, que colaboram na preservação do patrimônio cultural do país e na ampliação dos suportes para a pesquisa em diferentes campos.

$\mathrm{Na}$ área esportiva, a gestão da informação e do conhecimento passou a ser uma estratégia para a gestão do esporte, ganhou espaço para o desenvolvimento de centros, redes e sistemas em âmbito nacional. Vale destacar as ações do Ministério do Esporte, que vêm sensibilizando os setores vinculados à Administração Esportiva Brasileira sobre a importância da informação e documentação esportiva no processo de qualificação das ações de gestão e, como resultado, demandas por políticas nacionais de preservação da memória do esporte já têm sido apresentadas.

Os centros de memória como espaços de informação e documentação sobre o esporte vêm sendo destacados no Brasil nos últimos quinze anos. Ligados inicialmente a universidades, instituições e clubes esportivos, esses centros têm desempenhado papel de grande importância para a área esportiva, uma vez que se destinam não somente a guardar objetos e documentos que revelam experiências vividas, mas, principalmente, a preservar e a transmitir informações de grande significado social, pois podem nos ajudar a entender o presente, dando respostas às nossas indagações.

Vago (2008), ao analisar esses centros, pondera que seus acervos podem conter diversos tipos de informações e documentos - objetos, textos, imagens, sons, vestuários, depoimentos orais e tantas outras formas de revelar ações de homens e mulheres, crianças, jovens, adultos e idosos, governos, entidades diversas, quer seja vivenciando, organizando ou usufruindo o esporte, os quais podem nos ajudar a compreender as diferentes representações aliadas ao esporte conforme ele foi se constituindo como prática presente na nossa sociedade. Mais do que compreender essa constituição, a memória pode nos ajudar a reinventar a prática esportiva, uma vez que a memória pode ser vista como uma forma de aposta no que está por vir, nos ajudar a inventar o presente e o futuro do esporte.

Mas como pensar a constituição dos centros de memória como lugar de guarda, conservação, preservação, formação e produção de história? 
Pensar os centros de memória - um misto de arquivo, biblioteca e museu - como instituições que tratam da preservação e da difusão do patrimônio cultural implica levar em conta que eles apresentam determinado discurso sobre a realidade. Esse discurso, como afirma Mário Chagas, "como é natural, não é natural e compõe-se de sons e de silêncios, de cheios e de vazios, de presença e de ausência, de lembranças e esquecimentos." (CHAGAS, 2006, p.30) Apresentam, assim, esses espaços, um discurso sobre a realidade que é fruto da escolha entre o esquecimento e a memória. E como a memória possui caráter seletivo que indica articulações de poder, poderá manter vivas, ou colocar no esquecimento, determinadas representações e identidades sociais.

Assim, o que se guarda nos nossos acervos é permeado de intencionalidades. Como retrata Le Goff (1997), o que sobrevive não é o conjunto daquilo que existiu, mas o resultado de escolhas. É guardado o que se tem interesse em preservar, pesquisar e divulgar. Fazendo mediação entre o passado e o presente, documentando usos, tradições, formas de expressão, os objetos e os documentos dos acervos podem nos revelar tanto a identidade do grupo a que pertenceram, como também daqueles que os preservaram. São, assim, espaços de disputa, de interesses, de conflitos.

Guardar acervos requer atenção e ações diferenciadas e necessárias para que os documentos e os objetos preservados possam ser colocados à disposição do público e a serviço da sociedade.

Os centros de memória, para lidarem com acervos patrimoniais, devem ter frentes de trabalho complementares tais como: a preservação, a pesquisa e a comunicação dos bens culturais. Com isso, o desenvolvimento articulado dessas ações evidencia esses centros como organismos ligados à informação.

A preservação, discutida no Calendário produzido pelo Museu Mineiro em 2005, é vista como vinculada à ideia de antecipar o perigo da destruição:

Em se tratando de bens culturais - materiais e imateriais - a preservação
alcança um sentido mais amplo, pois o ato de preservar inclui desde a
identificação, passando pela aquisição ou registro, até a conservação física
propriamente dita desses bens, envolvendo todas as medidas necessárias a
sua proteção. O patrimônio cultural também é preservado por meio da
instituição de leis e normas específicas, ato de vontade com caráter seletivo.
(MINAS GERAIS. Secretaria de Estado da Cultura, 2005)

Nesse sentido, uma das principais maneiras de preservar a memória é produzir conhecimento sobre ela. Um programa de pesquisa permanente envolve a investigação e a documentação dos testemunhos da cultura e da história para a produção de 
conhecimento. E com a comunicação, as ações de pesquisa e preservação ganham seu sentido pleno, ou seja, o de ser comunicadas ao público e o de receber dele problematizações e interpretações que alimentarão novas pesquisas.

Como esse processo está sendo articulado no Centro de Memória e Informação do Esporte da Secretaria de Estado de Esportes e da Juventude - SEEJ - do Centro de Memória e Informação do Esporte - CEMIE?

A Administração Pública do Estado de Minas Gerais vem, desde os meados da década de 1990, valorizando a modernização de seus arquivos documentais por meio de um programa de Gestão de Documentos, com vista à racionalização e à eficiência administrativa, bem como à preservação do patrimônio documental de interesse histórico-cultural.

Além disso, a SEEJ, criada em 2007, com base na reestruturação do Governo mineiro, tem como proposta, em especial, a promoção de ações que visem à preservação e à recuperação da memória esportiva no Estado. Nesse sentido, foi instituída uma Diretoria de Memória e Informação, com a competência de criar de um centro de memória e informação esportiva.

O investimento na preservação da memória esportiva, tendo em vista o não esquecimento, nos remete a Harald Weinrich (2001). Ao analisar a linguagem do esquecimento em diferentes idiomas, o autor comenta que a mais eficiente de todas as imagens e comparações do esquecimento vem do mito dos primeiros tempos gregos, Hesíodo e Píndaro:

\begin{abstract}
Nos gregos, Letes é uma divindade feminina que forma um par constante com Mnemosyne, deusa da memória e mãe das musas. [...] Mas [sobretudo] Lete [ele ou ela] é [...] nome de um rio do submundo, que confere esquecimento às almas dos mortos. Nessa imagem e campo de imagens o esquecimento está inteiramente mergulhado no elemento líquido das águas. Há um profundo sentido simbólico dessas águas mágicas. Em seu macio fluir desfazem-se os contornos duros da lembrança da realidade, e assim são "liquidados". (WEINRICH, 2001, p.24 - grifos nossos)
\end{abstract}

Para evitar essa liquidação da memória do esporte em Minas Gerais, foi criado o CEMIE. Sua implantação, no entanto, vem sendo permeada por algumas dificuldades como, por exemplo, a carência de espaço físico para sua instalação. Localizado, hoje, na sala 124 do Estádio Magalhães Pinto - Mineirão -, o CEMIE vem cumprindo sua missão de preservar a memória do esporte mineiro. 
Seu objetivo inicial foi, não somente, resgatar a memória das políticas estatais de esporte, mediante a recuperação dos acervos documentais dos órgãos responsáveis pelo desenvolvimento dessas políticas, reconstruindo sua história, preservando e disponibilizando esse acervo, como também resgatar a memória esportiva do Estado, realizando parcerias intra e intergovernamentais e com a iniciativa privada, organizando essas informações e facilitando o acesso a elas, na busca de constituir-se como lugar da memória esportiva de Minas Gerais.

A Gestão para resultados do governo mineiro tem pactuado com os órgãos metas desafiadoras em busca da melhoria na qualidade dos serviços prestados à comunidade. A consolidação do CEMIE é uma das ações pactuadas pela Diretoria de Memória e Informação no Acordo de Resultados da SEEJ.

Cientes de que a memória pode servir tanto para a dominação e a domesticação dos homens quanto para a libertação deles, como afirma Le Goff (1992), esse reconhecimento nos permite pensar, com a ajuda de Chagas (2006), em criar não um lugar celebrativo da memória do poder, mesmo estando aliado ao Estado, mas um lugar da memória voltado democraticamente para o trabalho com o poder da memória, a serviço do desenvolvimento social.

Buscando preservar a memória esportiva e colocá-la a serviço da cidadania, o CEMIE não está sendo estruturado como um depósito de documentos antigos, organizados de forma tradicional. Além de ser um setor responsável por preservar a memória da Secretaria e do esporte mineiro, tem como meta oferecer informações para pesquisadores, estudantes e público em geral, disponibilizando seu acervo de diversas formas: via computador, catálogos bibliográficos, exposições, mostras fotográficas, palestras, oficinas, cursos e resultados de pesquisa. Com isso, espera-se consolidar o CEMIE como um local de referência para a pesquisa em história do esporte no estado de Minas Gerais.

As ações iniciais objetivaram localizar o então chamado arquivo morto da SEEJ, no qual se esperava resgatar grande parte da memória das políticas públicas de esporte. Em mau estado de conservação e organização, decorrente da falta de valorização dos arquivos pelas administrações anteriores, aliada ao extravio resultante de várias mudanças não somente de endereços, como também de ligações a diferentes órgãos, foram encontrados setecentos metros lineares de documentos. 
Uma pesquisa na legislação sobre os órgãos responsáveis pelas políticas públicas de esporte foi realizada para a análise do acervo, com o objetivo de identificar se nos arquivos havia documentos referentes a todos eles.

Diante do resultado dessa pesquisa, pouco pôde-se fazer, pois, como os documentos necessitavam passar por uma fase de higienização, dado o estado em que se encontravam, ainda não foi possível identificar a sua procedência e realizar a gestão documental. Somente em parte desse acervo, referente aos documentos das últimas administrações, é que foi possível realizar uma primeira identificação dos órgãos.

Algumas pistas mostram que o acervo procede da Diretoria de Esportes de Minas Gerais, célula mater da SEEJ, que foi um órgão gestor do esporte mineiro nas décadas de 1940 a 1980. A maioria desses documentos, de algum modo, foi perdida em administrações anteriores ou foi possivelmente descartada durante as mudanças pelas quais o órgão passou.

A recuperação, a organização, a preservação e a disponibilização desse acervo é a meta do CEMIE, e a memória das políticas públicas do esporte foi o foco de suas ações em 2008.

Realizou-se, no mês de agosto, o I Seminário do Centro de Memória e Informação do Esporte, cujo tema foi a Memória das Políticas Públicas de Esporte no Estado de Minas Gerais, contando com o apoio do Centro de Memória da Educação Física - CEMEF - da Escola de Educação Física, Fisioterapia e Terapia Ocupacional EEFFTO - da Universidade Federal de Minas Gerais - UFMG e do curso de Educação Física da Pontifícia Universidade Católica de Minas Gerais - PUC Minas. Além de possibilitar discussões sobre os percursos históricos do processo de consolidação das políticas públicas de esporte, o seminário contou com a participação de pessoas que vivenciaram essas políticas em solo mineiro, em diferentes momentos históricos, relatando experiências e memórias. $\mathrm{O}$ evento foi fundamental para a tomada de decisões em relação a uma política de preservação da memória do esporte em Minas Gerais. E o interesse na divulgação dessa memória, durante o evento, foi motivador para a realização de uma pesquisa sobre a trajetória dessa política, que foi apresentada, também, em uma linha do tempo, em forma de banner.

O acervo do CEMIE vem sendo constituído com a captação de documentos do arquivo da SEEJ e de algumas cidades do interior, dentre os quais se destacam objetos tridimensionais - medalhas e troféus -, fotografias, fitas de vídeo, documentos de 
divulgação como cartilhas, folders, banners; revistas, jornais e livros; além de documentações atuais das ações da Secretaria, como forma de preservar essa memória.

Essa diversidade de documentos e artefatos tem sido organizada de forma preliminar, no intuito de identificar possíveis coleções, uma vez que o processo de catalogação está apenas se iniciando. Como a Secretaria não possui pessoal especializado em arquivos, museus e bibliotecas, o CEMIE contou, inicialmente, com o apoio do Instituto Estadual do Patrimônio Histórico e Artístico - IEPHA -, que cedeu um funcionário para auxiliar o processo.

Para a constituição do Centro de Memória com condições adequadas de guarda, conservação, preservação, formação e produção de história sobre o esporte mineiro, alguns desafios ainda precisavam ser vencidos. O grande desafio para o ano de 2009 foi a proposição de uma Política de Preservação da Memória do Esporte para Minas Gerais.

Para que a Secretaria de Estado de Esporte e Juventude pudesse, efetivamente, promover ações que visassem a preservação e a recuperação da memória esportiva no Estado, como prevê a Lei Delegada $n^{0}$. 121, de 2007, fazia-se necessária a criação de uma política pública que pudesse traduzir-se em ações consistentes para essa preservação.

Um dos objetivos do I Seminário realizado pelo CEMIE foi a proposição dessa política para Minas Gerais. Convidado para fazer uma reflexão sobre a temática, o professor Tarcísio Mauro Vago, da EEFFTO/UFMG, iniciou um debate para sua elaboração. Como fruto dos debates realizados, foi aprovada, pela plenária final do Seminário, a proposta de constituição, pela SEEJ e pela Secretaria de Estado de Cultura - SEC -, de uma comissão especial para elaborar um documento apresentando as orientações e as diretrizes para a formulação da almejada Política Estadual de Preservação da Memória do Esporte. Nessa ocasião, definiu-se, também, que representantes da SEEJ, da SEC, da Assembleia Legislativa e de instituições de ensino superior deveriam compor a comissão.

Acatando essa deliberação, a SEEJ e a SEC baixaram a Resolução Conjunta ${ }^{\circ}$. 09/2009, de 20 de março de $2009^{1}$, criando a referida comissão especial com o objetivo

\footnotetext{
${ }^{1}$ Resolução Conjunta SEEJ-SEC, nº. 09, de 20 de março de 2009, publicada no dia 9 de abril no Diário Oficial de Minas Gerais. Como aprovado, ela foi composta pelos representantes da Secretaria de Estado de Esportes e da Juventude: Prof. Dra. Marilita Aparecida Arantes Rodrigues; da Secretaria de Estado da Cultura - Superintendência de Museus -: a historiadora Maria Inez Cândido; do Instituto Estadual do Patrimônio Histórico e Artístico de Minas Gerais: a historiadora Evelyn Maria de Almeida Meniconi; do Arquivo Público Mineiro: a historiadora Rosana de Figueiredo Ângelo; da Assembleia Legislativa: Prof. Dra. Deputada Gláucia Brandão; da Pontifícia Universidade Católica de Minas Gerais: Profa. Dra.
} 
de subsidiar a formulação da política. Após cumprir seu propósito, essa comissão apresentou à SEEJ um documento do qual destaca-se aqui algumas proposições.

O objetivo norteador do trabalho da comissão foi valorizar o CEMIE como um órgão gestor e executor da política e assegurar que ele se torne um órgão que permaneça para além das mudanças de interesse de um dado momento político, fazendo da iniciativa não uma política de governo, mas sim uma política de Estado. A ele foi dada a missão de recolher, reunir, conservar e difundir registros da história e da memória do esporte em Minas Gerais, de forma a institucionalizar e consolidar, em seu espaço, um conjunto de ações voltadas para a investigação, a preservação e a comunicação do seu acervo.

Assim, do ponto de vista conceitual, o CEMIE, integrando-se ao sistema de preservação do patrimônio cultural, foi definido como instituição museológica amparada na Lei Federal $n^{\circ} .11 .904$, de 14 de janeiro de 2009. ${ }^{2}$ Nessa perspectiva, seu papel é criar métodos e mecanismos que permitam o acesso às informações sobre os objetos/documentos que se encontram sob sua guarda, visando estabelecer a intermediação institucionalizada entre a comunidade mineira e o acervo preservado.

O documento apresentado, além de abordar elementos teóricos conceituais e metodológicos, bem como fundamentos legais e responsabilidades executivas, apresenta, à SEEJ, recomendações de medidas necessárias para a implantação e o funcionamento do CEMIE como órgão responsável pelo planejamento, coordenação e execução da política de preservação da memória do esporte em Minas Gerais.

Dentre as finalidades precípuas do CEMIE estão a guarda, a preservação e a divulgação de documentos e artefatos diversos relativos à memória do esporte em Minas Gerais; a promoção, a aplicação e a disseminação de conceitos e práticas que

Eustáquia Salvadora de Sousa; da UFMG - Centro de Memória da Educação Física, do Esporte e do Lazer da EEFFTO -: Prof. Dr. Tarcísio Mauro Vago. A comissão contou, também, com a assessoria da historiadora Francina Maria Monteiro Ribeiro e do advogado José Eustáquio Gonçalves Lima, assessores parlamentares da Deputada Gláucia Brandão.

${ }^{2}$ Lei $\mathrm{n}^{\circ}$. 11.904, de 14 de janeiro de 2009: "Capítulo 1, Disposições Gerais: Art. 1ํㅡㄴ Consideram-se museus, para os efeitos desta Lei, as instituições sem fins lucrativos que conservam, investigam, comunicam, interpretam e expõem, para fins de preservação, estudo, pesquisa, educação, contemplação e turismo, conjuntos e coleções de valor histórico, artístico, científico, técnico ou de qualquer outra natureza cultural, abertas ao público, a serviço da sociedade e de seu desenvolvimento. Parágrafo único. Enquadrar-se-ão nesta Lei as instituições e os processos museológicos voltados para o trabalho com o patrimônio cultural e o território visando ao desenvolvimento cultural e socioeconômico e à participação das comunidades. Art. $2^{\mathrm{o}}$ São princípios fundamentais dos museus: I - a valorização da dignidade humana; II - a promoção da cidadania; III - o cumprimento da função social; IV - a valorização e preservação do patrimônio cultural e ambiental; V - a universalidade do acesso, o respeito e a valorização à diversidade cultural; VI - o intercâmbio institucional." 
visem ao incentivo, à valorização e ao aprimoramento das atividades voltadas para a preservação da memória esportiva no Estado, orientando, sensibilizando e propondo, aos diferentes atores sociais responsáveis pela promoção do esporte, ações para a preservação da sua memória; o estabelecimento de convênios e parcerias com municípios, escolas, clubes, universidades, federações e outras entidades e instituições ligadas ao esporte. Organizar e promover esse processo é interesse da SEEJ, mas isso exige responsabilidades de todos os atores envolvidos com a promoção do esporte.

Incentivar a criação de centros congêneres ao CEMIE em todo o Estado, apoiando-os e subsidiando-os na elaboração e execução de planos, programas e projetos correlatos, atuando como unidade de integração e intercâmbio entre eles e instituições afins, é também uma das finalidades do CEMIE. Essas ações conduzirão à criação de uma Rede Estadual de Memória do Esporte, tendo como meta a construção de um sistema de informações da memória do esporte.

A SEEJ, hoje, está implantando uma cultura territorial para suas ações esportivas, as quais podem também estar voltadas para a preservação da memória. São doze territórios ou seis macroterritórios. Se cada centro criado no interior estiver conectado em rede aos seus polos territoriais, visando atender às necessidades de informação em cada região, e todos estiverem conectados ao Centro de Memória, teremos uma rede de memória esportiva que pode documentar e informar sobre a memória do esporte mineiro. É essencial que, com tecnologias de informação e comunicação, seus acervos sejam disponibilizados em páginas na internet, em catálogos e em cartilhas.

Com essas iniciativas e tantas outras ainda a estruturar, poderemos fazer do CEMIE e seus congêneres, espalhados pela capital e pelo interior, lugares de memória que produzam pesquisas e atendam à demandas para o desenvolvimento de estudos e pesquisas, de estudantes e professores de todos os níveis de educação e pesquisadores. Essas ações poderão contribuir para o alargamento de nosso conhecimento sobre a história do esporte em nosso Estado.

Para que esse processo seja realizado, faz-se necessário articular, com a Secretaria de Cultura, dentre outras ações, a qualificação de pessoal especializado para trabalhar na preservação, organização e difusão de acervos de memória do esporte.

Por outro lado, a realização de seminários, exposições e mostras que tematizem a memória do esporte, em Minas Gerais, a promoção de oficinas temáticas sobre sua história e o fomento a publicações individuais e coletivas na área serão fundamentais 
para que o CEMIE, como parte integrante dos sistemas de preservação do patrimônio cultural, assuma seu compromisso social, criando possibilidades de acesso à cultura e à construção da cidadania.

Para que isso seja uma realidade, é preciso investimento. Propor a instituições públicas e privadas medidas necessárias para a criação de linhas de financiamento que apoiem projetos de memória do esporte é também uma das metas do CEMIE.

Uma ação que merece destaque foi a conquista, em 2009, junto ao Fundo de Amparo à Pesquisa do Estado de Minas Gerais - FAPEMIG -, de um edital para apoiar a pesquisa na área da história do esporte e a preservação de acervos. Foram aprovados onze projetos, que receberam, juntos, a quantia de $\mathrm{R} \$ 509.652,82$. Além de financiar projetos de preservação, organização e disponibilização de fontes de pesquisa sobre a história do esporte mineiro, o edital contribuiu para a indução e a consolidação de grupos de estudo e pesquisa sobre a história do esporte em Minas Gerais.

Nesse processo, o CEMIE, em parceria com o grupo de estudos de políticas públicas da UFMG, o Grupo de Estudos em Políticas Públicas de Esporte e Lazer POLIS - e o Centro de Estudos de Lazer e Recreação - CELAR -, teve um projeto aprovado que irá resgatar e analisar a trajetória histórica das políticas públicas de esporte no Estado de Minas Gerais, no período de 1938 a 2006. Além de recuperar e analisar essa trajetória, objetiva-se, com o projeto, recuperar os acervos das diferentes administrações que foram responsáveis pelas políticas públicas de esportes em Minas e disponibilizar esse acervo levantado no CEMIE de forma física e digital. Como é um projeto de grande porte, ele foi apresentado, também, ao Ministério do Esporte, que está apoiando-o.

Mas, para que o CEMIE possa, realmente, cumprir sua função de órgão gestor e executor dessa política, conforme sugestão da Comissão Especial, faz-se necessário assegurar, por meio de legislação específica, a Política Estadual de Preservação da Memória do Esporte e elaborar o Plano Museológico do CEMIE, com vista a garantir, por meio das medidas administrativas e jurídicas adequadas, que o Centro disponha de corpo técnico e administrativo qualificado e suficiente para montagem, organização, funcionamento, manutenção e conservação dos bens sob sua guarda; espaço físico próprio, adaptado às indicações técnicas para exposição, comunicação, pesquisa e conservação de seu acervo e recursos materiais e financeiros indispensáveis ao seu funcionamento e ao cumprimento de suas finalidades. Deve ser estimulada, ainda, a criação de Associação de Amigos do CEMIE-MG, entidade civil sem fins lucrativos, 
para promover a valorização do Centro e propugnar pelo seu aprimoramento administrativo, técnico e cultural.

Nesse sentido, o grande desafio do Centro de Memória, em 2010, será ver a concretização a Política de Preservação da Memória do Esporte no Estado de Minas Gerais.

\begin{abstract}
This article presents the importance of information and the preservation of memory nowadays and analyzes the formation of memory centers as a place of preservation, research, communication, production and reproduction of historical knowledge. It focuses on the story of the experience of the Centro de Memória e Informação do Esporte (Memory and Information Center of Sports) - CEMIE - created in the Secretaria de Estado de Esportes e da Juventude de Minas Gerais (Ministry of Sports and Youth of Minas Gerais) SEEJ - as a public policy of preservation of the memory of Minas Gerais' sports.
\end{abstract}

Keywords: Memory centers; Sports; Public policies; Minas Gerais.

\title{
Referências
}

BRASIL. Lei n. 11.904, de 14 de janeiro de 2009. Institui o estatuto de museus e dá outras providências. Diário Oficial da União, Poder Executivo, Brasília, DF, 15 jan 2009.

CHAGAS, M. S. Há uma gota de sangue em cada museu: a ótica museológica de Mário de Andrade/Mário de Souza Chagas. Chapecó: Argos, 2006.

D’ALÉSSIO, M. M. Memória: leituras de M. Halbwachs e P. Nora. Revista Brasileira de História, v. 13, n. 25/26, p. 97-103, set 1992/ago 1993.

HUYSSEN, Andréas. Seduzidos pela memória, Rio de Janeiro, RJ: Aeroplano Ed. Universidade Cândido Mendes; Museu de Arte Moderna do Rio de Janeiro, 2000.

LE GOFF, Jacques. História e memória. 2. ed. Campinas, SP: Editora da Unicamp, 1992. 
MINAS GERAIS. Lei-Delegada n. 121, de 25 de janeiro de 2007. Dispõe sobre a organização da Secretaria de Estado de Esportes e da Juventude - SEEJ. Minas Gerais, Diário do Executivo, Belo Horizonte, col. 1, p. 9, 26 jan. 2007.

RODRIGUES, Marilita Aparecida Arantes; et al. Subsídios para formulação de política estadual de preservação da memória do esporte no estado de Minas Gerais. Belo Horizonte: SEEJ, 2008.

SECRETARIA DE ESTADO DA CULTURA DE MINAS GERAIS/SUPERINTENDÊNCIA DE MUSEUS. Calendário. Belo Horizonte: Museu Mineiro, 2005.

SECRETARIA DE ESTADO DE ESPORTES E DA JUVENTUDE/SECRETARIA DE CULTURA. Resolução Conjunta SEEJ/SEC n. 09/2009, de 20 de março de 2009. Minas Gerais, Belo Horizonte, 9 abr. 2009.

VAGO, Tarcísio Mauro. Por uma política de preservação da memória do esporte em Minas Gerais. Palestra proferida no I Seminário do Centro de Memória e Informação do Esporte, 22 ago 2008.

WEINRICH, Harald. Lete: arte e crítica do esquecimento. Rio de Janeiro: Civilização Brasileira, 2001. 